\title{
Antibody-enhanced cross-presentation of self antigen breaks $T$ cell tolerance
}

\author{
Stephanie O. Harbers, ${ }^{1}$ Andrea Crocker, ${ }^{1}$ Geoffrey Catalano, ${ }^{1}$ Vivette D'Agati, ${ }^{2}$ \\ Steffen Jung, ${ }^{3}$ Dharmesh D. Desai, ${ }^{1}$ and Raphael Clynes ${ }^{1}$
}

1Departments of Microbiology and Medicine and 2Department of Pathology, College of Physicians and Surgeons, Columbia University, New York, New York, USA. ${ }^{3}$ Department of Immunology, Weizmann Institute of Science, Rehovot, Israel.

\begin{abstract}
We have developed a model of autoimmunity to investigate autoantibody-mediated cross-presentation of self antigen. RIP-mOVA mice, expressing OVA in pancreatic $\beta$ cells, develop severe autoimmune diabetes when given OT-I cells (OVA-specific CD8 ${ }^{+} \mathrm{T}$ cells) and anti-OVA IgG but not when given $\mathrm{T}$ cells alone. Anti-OVA IgG is not directly injurious to the islets but rather enhances cross-presentation of apoptotic islet antigen to the OT-I cells, leading to their differentiation into potent effector cells. Antibody-driven effector $T$ cell activation is dependent on the presence of activating Fc receptors for IgG $(\mathrm{Fc} \gamma \mathrm{Rs})$ and cross-priming DCs. As a consequence, diabetes incidence and severity was reduced in mice lacking activating $\mathrm{Fc} \gamma \mathrm{Rs}$. An intact complement pathway was also required for disease development, as $\mathrm{C} 3$ deficiency was also partially protective. C3-deficient animals exhibited augmented $T$ cell priming overall, indicating a proinflammatory role for complement activation after the $T$ cell priming phase. Thus, we show that autoreactive antibody can potently enhance the activation of effector $T$ cells in response to cross-presented self antigen, thereby contributing to $T$ cell-mediated autoimmunity.
\end{abstract}

\section{Introduction}

In models of autoimmune thrombocytopenia, hemolytic anemia, and systemic lupus erythematosus, antibody-opsonized cells or deposited immune complexes (ICs) trigger complement activation and engagement of $\mathrm{Fc}$ receptor for $\operatorname{IgG}(\mathrm{Fc} \gamma \mathrm{R})$ on innate immune cells. This leads to cellular cytotoxicity and tissue injury via activation of inflammatory pathways. In this paradigm, the pathogenicity of autoantibodies is limited to their role as direct inducers of the immune effector response. However, the opsonic capacity of antibodies also promotes antigenic uptake by Fc $\gamma$ Rs and/or complement receptors on APCs, thereby potentially affecting the priming phase of autoaggressive T cells. This APC-mediated pathway therefore broadens the potential pathogenic involvement of the humoral response to include autoimmune states in which $\mathrm{T}$ cells are the dominant mediators of tissue injury.

Based on their potent uptake and antigen presentation capacity, DCs would be expected to be the APCs linking ICs with their effects on T cell priming. Studies on cultured DCs have demonstrated that uptake of antigen through activating $\mathrm{Fc} \gamma \mathrm{Rs}$ leads to rapid targeting of the antigen to the lysosomal compartment. This in turn provides access to both the exogenous and cross-presentation processing pathways, enabling efficient loading of the antigen onto both MHC class I and II molecules (1-3). Additionally, engagement of activating Fc $\gamma$ Rs induces DC maturation via an immunoreceptor tyrosine-based activation motif/syk-mediated (ITAM/syk-mediated) signaling pathway (4). Thus, antigenic targeting to activating Fc $\gamma$ Rs on DCs fulfills the essential requirements for the induction of $\mathrm{CD}^{+}$and $\mathrm{CD}^{+} \mathrm{T}$ cell effector responses: high-level loading of $\mathrm{MHC}$ class I and II (signal 1) and provision of costimulatory molecules on the surface of mature DCs (signal 2), as well as the elaboration of

Nonstandard abbreviations used: BMDC, BM-derived DC; DT, diphtheria toxin; DTR, diphtheria toxin receptor; Fc $\gamma$ R, Fc receptor for IgG; IC, immune complex; ITAM, immunoreceptor tyrosine-based activation motif; rIgG, rabbit IgG.

Conflict of interest: The authors have declared that no conflict of interest exists. Citation for this article: J. Clin. Invest. 117:1361-1369 (2007). doi:10.1172/JCI29470. immunostimulatory cytokines (5). Conversely, the presence of the inhibitory Fc $\gamma$ RIIB on DCs serves to limit antigen trafficking to the degradative lysosomal compartment, inhibit ITAM-mediated DC activation, and diminish effector $T$ cell responses (1, 5-7).

Immunization of mice with DCs that have taken up ICs via their activating $\mathrm{Fc} \gamma \mathrm{Rs}$ can induce potent effector $\mathrm{CD} 4^{+}$and $\mathrm{CD} 8^{+} \mathrm{T}$ cell responses that are sufficient to provide tumor immunity $(6,8)$. These studies highlight the potential for targeting of activating Fc $\gamma$ Rs on DCs for the induction of $\mathrm{T}$ cell responses to exogenous antigens and suggest that such targeting by autoantibodies could alter the balance of DC-mediated peripheral $\mathrm{T}$ cell tolerance by provision of both signals 1 and 2 in the context of a self antigen.

Opsonization of antigen by complement enables engagement of several potential receptors on DCs, including C1q and CR2-4. Prior work has suggested important roles for complement as both an enhancer of responses to exogenous antigens (9-11) and a mediator of tolerance (12-14). Complement binds to apoptotic cells via "natural" antibody or direct binding by the collectin C1q (15) and has been thought to contribute to benign clearance of these cellular corpses (16-18) by phagocytes, including DCs (13), thereby reinforcing peripheral $\mathrm{T}$ cell tolerance $(14,17,18)$. Indeed complement deficiency is associated with inefficient clearance of apoptotic cells and with SLE in both humans $(19,20)$ and genetically manipulated mice $(21,22)$.

We have developed a novel mouse model of $\mathrm{T}$ cell-mediated diabetes to investigate whether antibodies reactive with islet antigen can participate in triggering $\mathrm{T}$ cell autoimmunity. Using this model we have specifically examined the contribution of activating Fc $\gamma$ Rs and complement to the cross-priming of autoreactive CD8 ${ }^{+}$ $\mathrm{T}$ cells. We show here that $\mathrm{F} \gamma \mathrm{R}$-mediated antigen presentation by DCs enhances diabetogenic CTL responses, providing direct evidence for a role for self-reactive antibodies in promoting the loss of T cell tolerance. Complement negatively regulates CTL priming by apoptotic self antigen yet is not required for antibody-driven CTL differentiation and likely contributes pathogenically to the autoimmune effector phase. 


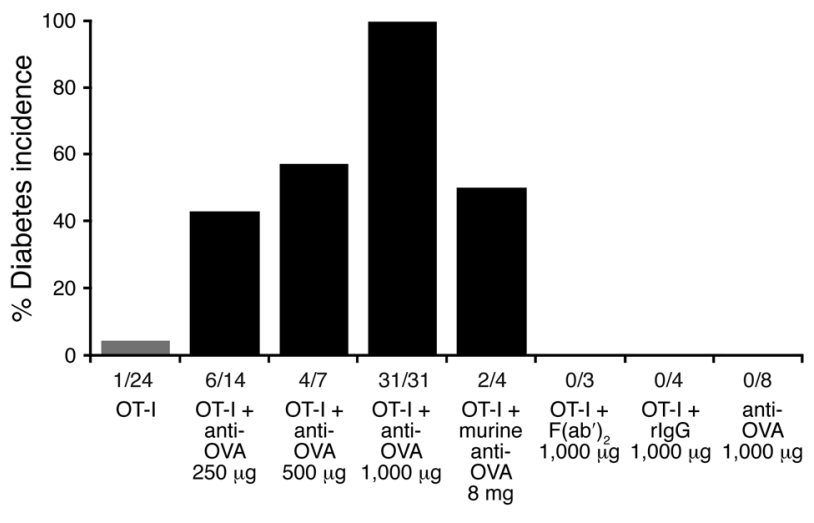

Figure 1

OT-I cells and anti-OVA IgG synergistically induce diabetes. Diabetes incidence: RIP-mOVA mice were injected with $5 \times 10^{6} \mathrm{OT}$-I cells alone or together with administration of rabbit anti-OVA IgG, control rlgG, an $\left.\mathrm{F}(\mathrm{ab})_{2}\right)_{2}$ fragment of rabbit anti-OVA IgG, or murine polyclonal anti-OVA IgG. Anti-OVA refers to rabbit anti-OVA IgG unless otherwise noted. Fractions below bars indicate the number of diabetic mice over the total number treated. Diabetes was not induced by transfer of OVAspecific antibodies and rarely by OT-I cells alone but was synergistically induced by transfer of both OT-I cells and anti-OVA IgG.

\section{Results}

Islet cell antigen reactive $C D 8^{+} T$ cells and antibody collaborate to cause autoimmune diabetes in RIP-mOVA mice. To directly examine the consequences of antibody-enhanced cross-priming in the context of autoantibody and self antigen in vivo, we have looked at the development of autoimmune diabetes in RIP-mOVA mice (23). These mice express the model antigen OVA as "self" in the thymus and the $\beta$ cells of the pancreas. Thymic expression of OVA leads to central tolerance; however, studies of peripheral tolerance are enabled by the transfer of OVA-specific naive T cells. Transfer of naive OT-I $\mathrm{CD}^{+}$transgenic $\mathrm{T}$ cells into RIP-mOVA adoptive recipients results in cross-tolerance due to OT-I deletional mechanisms (24). Loss of self tolerance is triggered either by the transfer of high numbers of OT-I cells or by the provision of T cell help (25), which leads to an OT-I CTL-mediated attack on the pancreatic islets of RIP-mOVA animals, resulting in diabetes. These studies utilized OT-I donor populations obtained from RAG1-/- backgrounds, while subsequent work in our laboratory has shown that $\mathrm{CD}^{+} \mathrm{T}$ cells obtained from OT-I TCR transgenic mice on conventional C57BL/ 6 backgrounds do not provoke diabetes even when transferred in large numbers (Supplemental Figure 1; supplemental material available online with this article; doi:10.1172/JCI29470DS1).

In our initial experiments, mice were injected with naive $\mathrm{CD} 8^{+}$ OT-I cells obtained from conventional OT-I TCR C57BL/6 mice, rabbit anti-OVA IgG, or both and then monitored over time for diabetes development. Staining of pancreatic cryosections showed that transferred rabbit anti-OVA IgG bound specifically to the islets of Langerhans in RIP-mOVA mice, approximating the expression pattern of OVA. However, despite binding, there was no evidence of a local pancreatic Arthus-like acute inflammatory response at 24 hours, nor was there any evidence of infiltration or glycosuria 7-20 days after the transfer of anti-OVA IgG alone (Figure 1 and Figure 2A; and data not shown). This data supports a lack of intrinsic pathogenicity of the antibody. In mice receiving OT-I cells alone, disease was extremely infrequent, with only 1 of
24 recipients developing diabetes, consistent with the induction of peripheral tolerance (Figure 1). Thus, neither anti-OVA IgG nor OT-I cells were capable by themselves of inducing diabetes. In contrast, when anti-OVA IgG was administered together with the OT-I cells, diabetes was synergistically induced in a manner dependent on the dose of the antibody, with all mice developing disease at $1,000 \mu \mathrm{g}$ of anti-OVA IgG (Figure 1). Diabetic animals sustained severe glycosuria (urine glucose $\geq 1,000 \mathrm{mg} / \mathrm{dl}$ ) and hyperglycemia (blood glucose $>400 \mathrm{mg} / \mathrm{dl}$ ), with a disease onset of 6-9 days after treatment. These findings clearly demonstrate the ability of antibody to drive T cell-mediated autoimmunity in this system.

No diabetes occurred with the transfer of OT-I cells and control nonimmune polyclonal rabbit $\operatorname{IgG}(\mathrm{rIgG})$, underscoring the requirement for islet-specific antibody in disease development (Figure 1). In addition, administration of $1,000 \mu \mathrm{g}$ of $\mathrm{a} F\left(\mathrm{ab}^{\prime}\right)_{2}$ fragment of the polyclonal rabbit anti-OVA IgG, along with OT-I cells, also did not cause diabetes, implicating the Fc portion of the antibody in disease development (Figure 1). To address the possibility that these results might simply demonstrate an effect of the xenogenic rIgG, polyclonal murine anti-OVA IgG was transferred into RIP-mOVA mice. Two of 4 mice receiving OT-I cells plus $8 \mathrm{mg}$ of the murine polyclonal antibody developed diabetes by day 7 (Figure 1), while transfer of murine anti-OVA IgG alone did not induce diabetes $(n=2)$. This shows that both rabbit and murine polyclonal anti-OVA IgG are able to induce diabetes synergistically with OT-I cells. The apparent greater potency of the rabbit anti-OVA IgG can be explained in part by the relative titers of the 2 polyclonal preparations. The rabbit anti-OVA IgG had a 44-fold higher OVA-binding activity than the murine anti-OVA IgG, making the 2 preparations relatively equal in terms of disease-inducing ability (Supplemental Figure 2).

Histologically, diabetes induced by combined OT-I cell and antiOVA IgG transfer was marked by widespread inflammatory lesions in the pancreata of all mice examined. Starting progressively on day 3 , lymphocytes were seen in perivascular regions and throughout the pancreatic exocrine tissue, as well as surrounding and infiltrating the islets of Langerhans. Numerous pyknotic nuclei were present, indicating cellular apoptosis of both the islet and adjacent acinar cells. By days 5-7, near obliterative lesions were seen in the remnant islets, coinciding with the appearance of severe glycosuria (Figure 2B and Table 1). As expected, immunofluorescence staining demonstrated numerous $\mathrm{CD}^{+}$cells within infiltrative islet lesions, and flow cytometric analysis showed a significant population of OT-I cells $\left(\mathrm{V} \alpha 2^{+} \mathrm{V} \beta 5^{+}\right)$within the pancreas of diabetic animals, consistent with OT-I CTL-mediated destruction (Figure 2, B and C). In the peri-islet areas, various other infiltrating cell types were also detect-

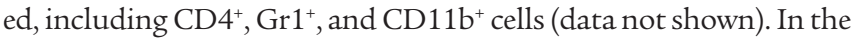
absence of antibody, very few lymphocytes entered the pancreas and neither inflammatory lesions nor intraislet $\mathrm{CD}^{+} \mathrm{T}$ cells were present (Figure 2, B and C). Thus, the cotransfer of autoreactive antibody was required to trigger massive OT-I cell-mediated inflammation and destructive insulitis in the pancreas of RIP-mOVA mice.

In vivo OT-I cell priming is enhanced by anti-OVA IgG. Antibody is known to augment uptake and processing of cognate antigen by DCs, leading to efficient $\mathrm{T}$ cell priming. Therefore, to address the mechanism by which anti-OVA IgG induces OT-I cells to cause diabetes, we began by looking at initial priming events in the draining pancreatic lymph node. RIP-mOVA mice received $5 \times 10^{6} \mathrm{CFSE}$-labeled OT-I cells with or without anti-OVA IgG, and proliferative responses were assessed 3 days later. As has been previously described (26), transferred OT-I cells underwent proliferation in the pancreatic lymph node, presumably 
A
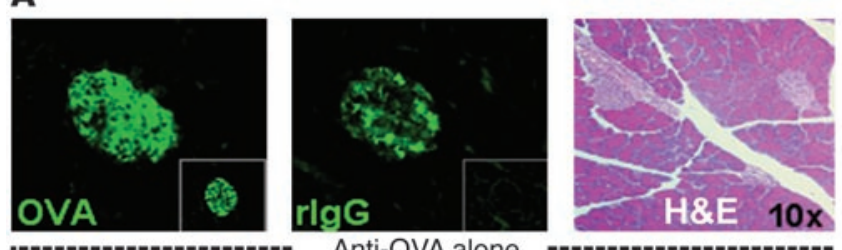

B

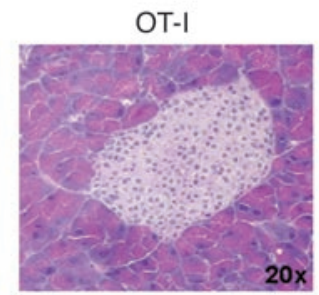

OT-I + anti-OVA
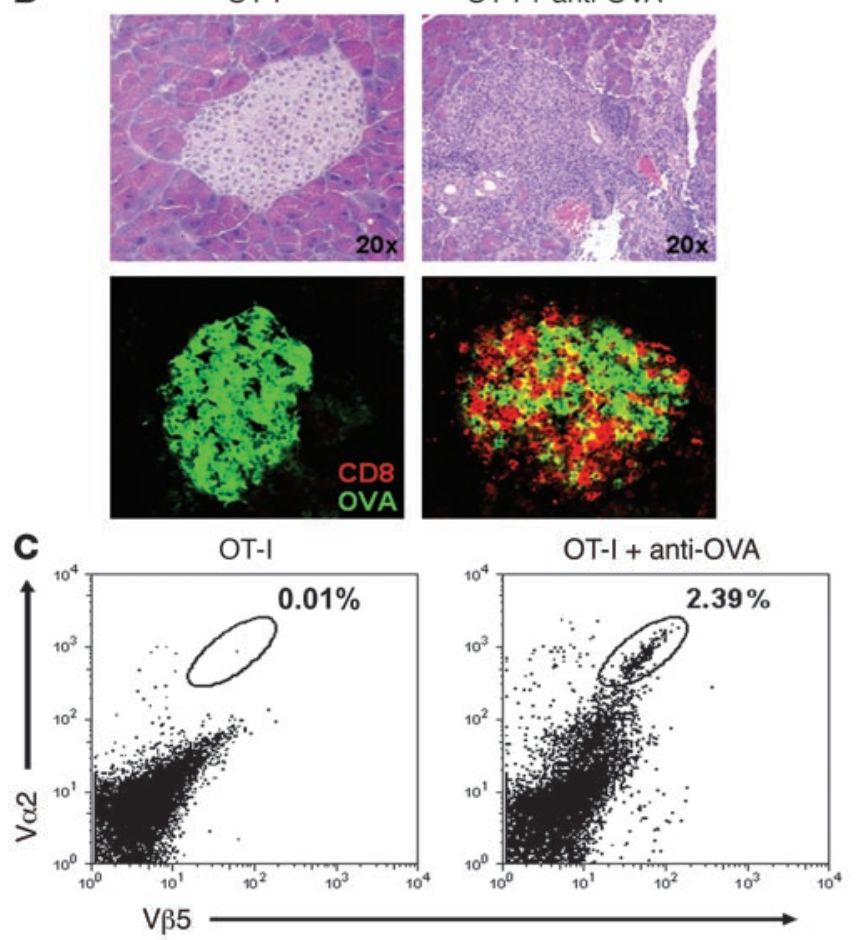

Figure 2

Anti-OVA IgG drives OT-I cell infiltration into the pancreas. (A) AntiOVA IgG binds to the islets of Langerhans without causing acute inflammation. Staining for OVA (left), bound anti-OVA IgG (by detecting rlgG; middle), and H\&E (right) in the pancreata of RIP-mOVA mice 24 hours after treatment with 1,000 $\mu \mathrm{g}$ anti-OVA IgG or $1,000 \mu \mathrm{g}$ control rlgG (insets). Transferred anti-OVA IgG bound to islet cells (middle) but did not trigger infiltrative lesions (right). (B and C) Diabetes results from OT-I cell infiltration into the pancreas. H\&E, CD8 (red), and OVA (green) staining on pancreatic sections (B) and flow cytometric analysis of total live pancreatic cells (C) from RIP-mOVA mice 7 days after transfer of either OT-I cells alone or together with $1,000 \mu \mathrm{g}$ anti-OVA IgG. V $\alpha 2$ and V $\beta 5$ indicate the presence of OT-I TCR ${ }^{+}$cells. Destructive cellular infiltrates were observed after the transfer of $T$ cells and anti-OVA IgG, including massive intraislet CD8+ OT-I cell accumulation, whereas $T$ cells transferred alone did not accumulate in the pancreas nor induced inflammatory responses.

due to ongoing cross-presentation of OVA by lymph node DCs. However, upon addition of anti-OVA IgG, OT-I cell proliferation was consistently amplified 1.5- to 2-fold (Figure 3A), indicating the ability of anti-OVA IgG to boost the presentation of OVA in the draining lymph node to incoming T cells. Furthermore, enhanced OT-I cell proliferation in the presence of anti-OVA IgG led to an even greater augmentation in effector OT-I cell differentiation, as assessed by IFN- $\gamma$ production 5 days after transfer. ELISPOT analysis showed a dramatic increase in the number of cells producing IFN- $\gamma$ in the pancreatic lymph node of antibody-treated mice compared with those receiving only $\mathrm{T}$ cells (Figure $3 \mathrm{~B}$ ). This effect was specific to the draining pancreatic lymph node, as IFN- $\gamma$ production was not similarly enhanced in the nondraining brachial lymph node and only slightly so in the spleen. In order to identify the specific cell population responsible for the IFN- $\gamma$ production, intracellular detection of this cytokine was performed. Gating on the transferred OT-I cell population showed that these cells were the primary producers of IFN- $\gamma$ in the pancreatic lymph node and that in the presence of rabbit anti-OVA IgG, 5 -fold more of these cells differentiated into IFN- $\gamma$-producing effectors (Figure 3C). Collectively, these data show that antibody not only enhances OT-I cell proliferation in the draining lymph node, but it also alters the qualitative outcome of self-antigen recognition, driving proliferating $\mathrm{T}$ cells to differentiate into effector CTLs.

Anti-OVA IgG enhances the presentation of apoptotic cell antigen. We sought to determine the nature of the antibody-opsonized antigen responsible for enhanced presentation in the pancreatic lymph node. AntiOVA IgG could bind to OVA on the membrane or OVA released from viable $\beta$ islet cells, as well as opsonized apoptotic $\beta$ islet corpses that are constantly being produced by steady-state $\beta$ cell death (27). To ascertain the role of apoptosis, RIP-mOVA mice were treated with the pancaspase inhibitor ZVAD, which has been used pharmacologically in a study implicating apoptotic cells as a source of antigenic material (27). Mice were treated with ZVAD 24 hours prior to the injection of antiOVA IgG and OT-I cells. Antibody-enhanced OT-I cell proliferation was abrogated in ZVAD-treated mice, indicating that apoptotic islet cells are the likely source of opsonized antigenic material (Figure 4). This effect was not due to enhanced $\beta$ islet cell apoptosis resulting from antibody binding, as islets from anti-OVA IgG- and rIgG-treated mice contained similar numbers of TUNEL-positive cells at 24 and 72 hours after antibody transfer (data not shown). Notably, steadystate OT-I cell proliferation in the pancreatic lymph node was not eliminated in ZVAD-treated mice, likely because apoptotic material persists in the node for more than 24 hours. Despite clear inhibition of the initial OT-I cell proliferative burst, reflective of decreased levels of antigen presentation, continued ZVAD treatment did not prevent the development of diabetes in RIP-mOVA mice $(n=5$; data not shown). The persistence of disease may result from the antiapoptotic effects of ZVAD on additional cellular targets, including the responding OT-I cells themselves, which would otherwise be deleted $(24,28)$. This idea is supported by the fact that inhibition of $\mathrm{T}$ cell expansion was no longer apparent by day 5 , when normal or increased numbers of OT-I cells were found in the pancreatic lymph nodes of ZVAD-treated animals (Supplemental Figure 3). Thus, despite the confounding effects of ZVAD on OT-I cell accumulation/survival, the early block of antibody-enhanced OT-I cell proliferation is directly indicative of the contribution of $\beta$ islet cell apoptosis to antigen presentation.

$D C$ are required for the in vivo cross-presentation of OVA. DCs have been implicated as the relevant cross-presenting cell for tolerogenic and diabetogenic presentation of islet antigen in the draining pancreatic lymph node (29). In ex vivo analysis, both CD11b-CD8 ${ }^{+}$ and CD11 $\mathrm{b}^{+} \mathrm{CD} 8^{-} \mathrm{DCs}$ have been shown to be responsible $(27,30)$. Therefore, we were interested in the importance of DCs for both the steady-state and antibody-enhanced proliferation seen in vivo in RIP-mOVA mice. To this end, we took advantage of CD11c-diphtheria toxin receptor (CD11c-DTR) mice, which express a human high-affinity DTR on the surface of $\mathrm{CD} 11 \mathrm{c}^{+}$cells, making them specifically sensitive to diphtheria toxin-mediated (DT-mediated) apoptosis (31). Using this DC depletion model, DCs have been previously shown to be required for the cross-presentation of cell-asso- 


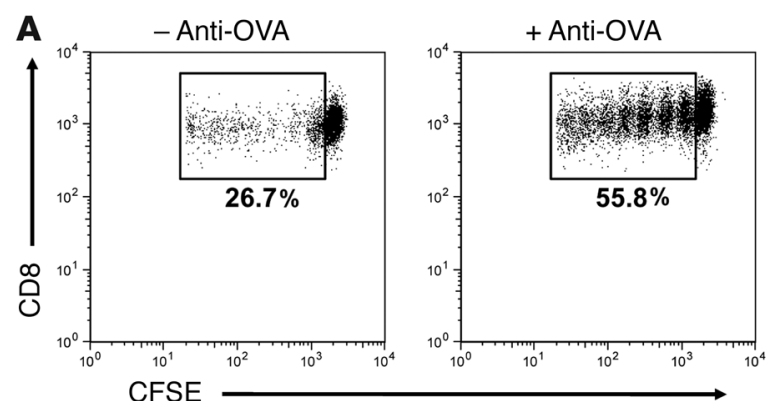

B
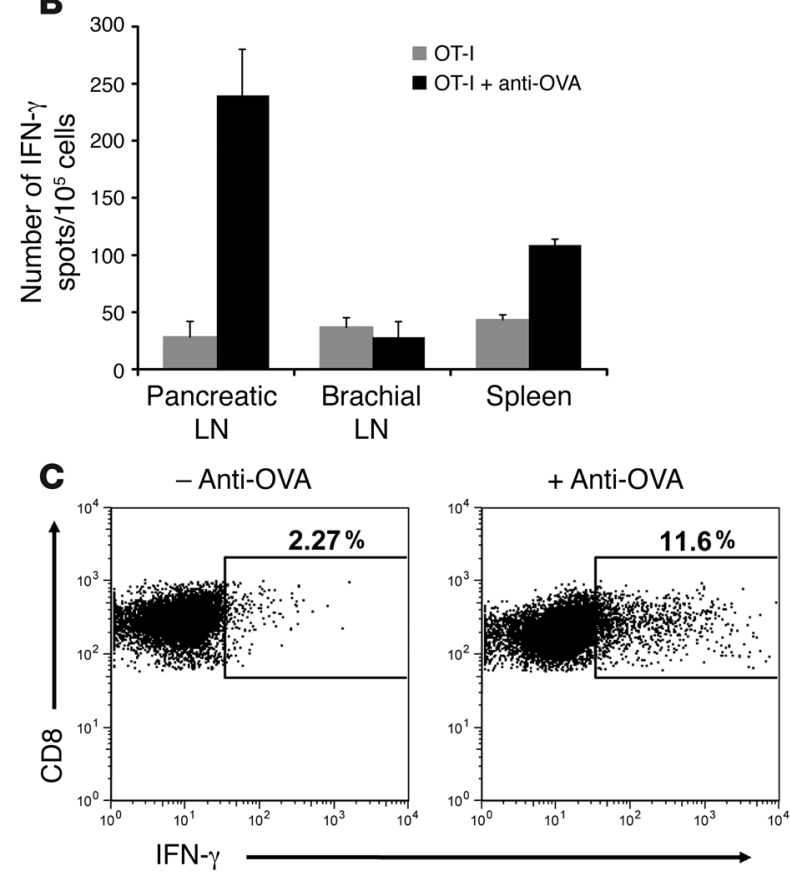

ciated (31) and soluble exogenous antigen (32), as well as for the presentation of bacterial $(31)$ and viral antigens $(33,34)$. Preliminary experiments in DT-treated WT and CD11c-DTR mice showed that transferred OT-I cells accumulated and localized to the T cell zones of the lymph nodes and spleen in comparable numbers regardless of the presence or absence of CD11 $\mathrm{c}^{+}$cells (Supplemental Figure 4). Therefore, DT-treated RIP-mOVA and RIP-mOVA/CD11c-DTR mice were transferred with $5 \times 10^{6}$ CFSE-labeled OT-I cells with or without anti-OVA IgG, and proliferation was assessed after 3 days. Strikingly, no proliferation of the OT-I cells was seen in the pancreatic lymph node of DC-depleted recipient mice, regardless of whether the mice also received anti-OVA IgG (Figure 5). In order to confirm our findings and rule out roles for subpopulations of marginal zone splenic macrophages (35), we transferred CD $11 \mathrm{c}^{+}$splenic cells isolated from WT mice into DT-treated RIP-mOVA/CD11c-DTR recipients and once again assessed OT-I cell proliferative responses. Reconstitution of RIP-mOVA/CD11c-DTR mice with $5 \times 10^{6}$ CD $11 \mathrm{c}^{+}$cells, injected i.v. prior to DT treatment, led to only $30 \% \mathrm{DC}$ reconstitution in the pancreatic lymph node. However, this transfer was sufficient to restore steady-state and antibody-triggered OT-I cell proliferation (Supplemental Figure 5). Therefore, these data cumulatively demonstrate that $\mathrm{CD} 11 \mathrm{c}^{+} \mathrm{DCs}$ are the required APCs for both steady-state and antibody-enhanced cross-presentation of self antigen in the pancreatic lymph node of RIP-mOVA mice.

\section{Figure 3}

Anti-OVA IgG enhances functional antigen presentation in the pancreatic lymph node. (A) OT-I cell proliferative responses. Pancreatic lymph node cells isolated from RIP-mOVA mice 3 days after transfer of CFSE-labeled OT-I cells and anti-OVA IgG. Dot plots are gated on $\mathrm{CD}^{+}{ }^{+} \mathrm{CFSE}^{+}$cells. Proliferation was enhanced 2 -fold in recipients of OT-I cells and anti-OVA IgG. (B and C) OT-I cell effector differentiation. ELISPOT analysis of IFN- $\gamma$ production by total lymph node and splenic cells (B) and intracellular IFN- $\gamma$ staining of pancreatic lymph node OT-I cells $(\mathbf{C})$ isolated from RIP-mOVA mice 5 days after treatment. Bars show mean \pm SD for triplicate wells of 1 representative experiment out of 3. Dot plots are gated on $\mathrm{CD} 8+\mathrm{V} \alpha 2^{+} \mathrm{V} \beta 5^{+}$cells. Differentiation of OT-I cells into IFN- $\gamma$-producing effectors was significantly $\left(P=1.06 \times 10^{-6}\right)$ enhanced in the presence of anti-OVA IgG.

We next examined whether immunization with OVA IC-loaded DCs was sufficient to break peripheral tolerance in RIP-mOVA mice. Animals were immunized intravenously with either OVAloaded or OVA IC-loaded BM-derived DCs (BMDCs), prior to the transfer of $5 \times 10^{6}$ OT-I cells. All 3 mice receiving OVA IC-loaded BMDCs developed diabetes, while none of 3 mice immunized with OVA-loaded BMDCs became diabetic (data not shown). Thus, the targeting of ICs to DCs is both necessary and sufficient for overcoming cross-tolerance in vivo.

Lethal induction of antibody-triggered diabetes requires activating $F c \gamma R$ s and complement. In order to determine the contribution of the activating $\mathrm{F} c \gamma \mathrm{R}$ and complement pathways to the antibody-triggered induction of CTL-mediated autoimmunity, RIP-mOVA Fc $\gamma \mathrm{R} \gamma^{-/-}$, RIP-mOVA $\mathrm{C}^{-/-}$, and RIP-mOVA Fc $\mathrm{R}^{-/-} \mathrm{C}^{-/-}$mice were generated. The absence of the $\gamma$ chain associated with Fc $\gamma \mathrm{RI}$, -III, and -IV prevents expression of these activating Fc $\gamma \mathrm{Rs}(36,37)$ on the cell surface, while $\mathrm{C}^{-/-}$mice can no longer carry out the classical or alternative complement cascades (38). Examination of these mice for disease development in response to the transfer of OT-I cells and anti-OVA IgG revealed that elimination of either activating $\mathrm{F} c \gamma$ Rs or $\mathrm{C} 3$ resulted in a significant, though not complete, reduction in disease incidence. Diabetes developed in approximately $40 \%$ of RIP-mOVA mice deficient in either Fc $\gamma$ R $\gamma$ or C3, compared with $100 \%$ of WT RIP-mOVA mice (Figure 6 A). In addition, the severity of the diabetic illness in mice lacking activat-

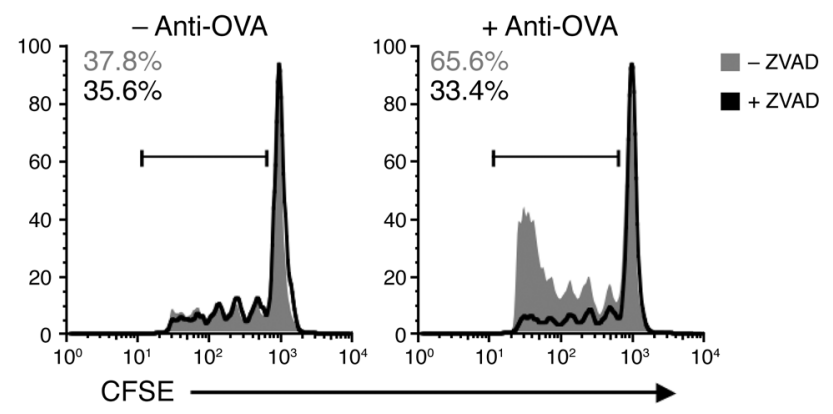

Figure 4

Anti-OVA IgG enhances OT-I cell proliferation in response to apoptotic cell antigen. Flow cytometric analysis of pancreatic lymph node cells isolated from ZVAD-treated and untreated RIP-mOVA mice 3 days after transfer of CFSE-labeled OT-I cells with or without antiOVA IgG. Histograms show percentage of cells divided relative to total $\mathrm{CD}^{+}{ }^{+} \mathrm{CFSE}^{+}$cells. Data represent 1 of 2 independent experiments. Antibody-enhanced OT-I cell proliferation was abolished in ZVADtreated mice (right). 


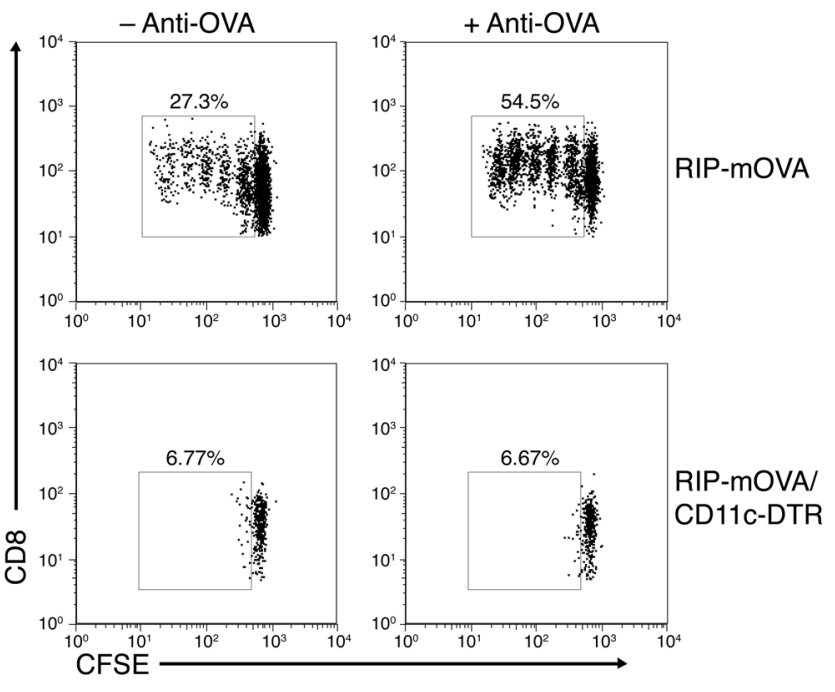

Figure 5

DCs are required for steady-state and antibody-enhanced OT-I cell proliferation in the pancreatic lymph node. Flow cytometric analysis of pancreatic lymph node cells isolated from DT-treated RIP-mOVA and RIP-mOVA/CD11c-DTR mice 3 days after transfer of CFSE-labeled OT-I cells alone (left panels) or together with anti-OVA IgG (right panels). Dot plots are gated on CD8 ${ }^{+} \mathrm{CFSE}^{+}$cells and represent 1 of 3 independent experiments. OT-I cell proliferative responses were abolished in the absence of DCs (bottom panels).

ing $\mathrm{F} c \gamma \mathrm{Rs}$ or $\mathrm{C} 3$ was greatly attenuated. These animals often exhibited only transient glycosuria (with a range of 12-152 days), and all mice survived their course of illness, whereas diabetes was unrelenting in all WT RIP-mOVA mice, resulting in $75 \%$ lethality by 47 days (Figure 6B). Histopathological scores of insulitis and exocrine tissue inflammation among groups were consistent with their respective disease incidences (Table 1). Notably, however, insulitis in recipients of OT-I cells alone was more prominent in RIP-mOVA C3-- mice than in the other genotypes. RIP-mOVA FcyR $\gamma^{-/-} \mathrm{C}^{-/-}$mice were completely protected from diabetes, with no mice developing glycosuria or hyperglycemia. These data indicate that complement and activating Fc $\gamma$ Rs are required together for maximal penetrance and severity of diabetes in recipients of anti-OVA IgG and OT-I cells.

Antibody-mediated cross-priming of self antigen is dependent on activating FcyRs and not on complement $C 3$. To address the mechanistic contributions of activating Fc $\gamma$ Rs and complement to the loss of tolerance in RIP-mOVA mice, we have assessed their requirement in antibody-mediated cross-priming in the draining pancreatic lymph node. Strikingly, RIP-mOVA mice lacking activating FcyRs no longer showed antibody-enhanced OT-I cell proliferation, while steady-state cross-presentation of OVA in the pancreatic lymph node was unchanged (Figure 7A). Further, intracellular cytokine staining revealed no significant antibody-driven enhancement of IFN- $\gamma$ production when activating Fc $\gamma$ Rs were absent (Figure 7C). Thus, while activating FcyRs on additional cell types may also ultimately contribute to pancreatic injury, these findings, in conjunction with the DC requirement for OT-I cell proliferation (Figure 5), indicate the importance of activating Fc $\gamma$ Rs on DCs in the cross-priming of $\mathrm{T}$ cells to antibody-bound islet antigen.

On the other hand, C3 was not required for antibody-enhanced cross-priming of the OT-I cells. Interestingly, however, the steady-state level of $\mathrm{T}$ cell proliferation was significantly enhanced in RIP-mOVA $\mathrm{C}^{-/-}$mice (Figure $7 \mathrm{~A}$ ). These data suggest a negative regulatory role for complement in steady-state antigen presentation in the pancreatic lymph node. In particular, C3 appeared to be regulating the cross-presentation of apoptotic material, as enhanced steadystate OT-I cell proliferation did not occur in ZVAD-treated animals (Figure 7B). Similar results were obtained when effector OT-I cell differentiation was assessed (Figure $7 \mathrm{C}$ ). In the absence of antibody, a 3 -fold greater frequency of IFN- $\gamma$-producing OT-I cells was generated in RIP-mOVA C3 $3^{-/}$mice compared with WT RIP-mOVA mice. However, in the presence of antibody, the frequency of OT-I effector cells increased further still, underscoring the lack of requirement for $\mathrm{C} 3$ in antibody-enhanced $\mathrm{T}$ cell priming.

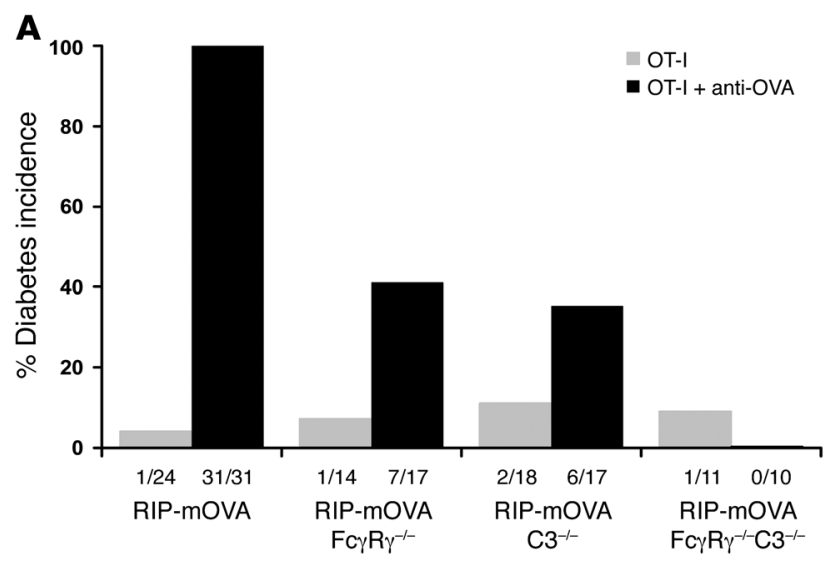

\section{B}

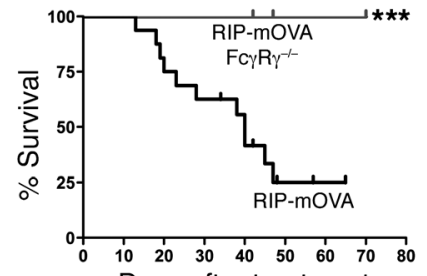

Days after treatment

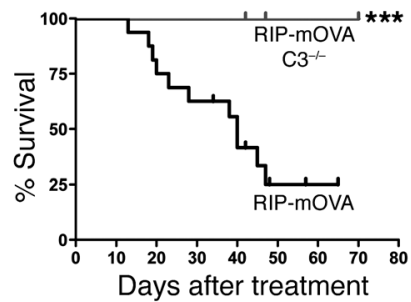

Days after treatment

\section{Figure 6}

Mice lacking activating Fcy receptors and complement are protected from severe antibody-induced diabetes. (A) Diabetes incidence. RIP-mOVA,

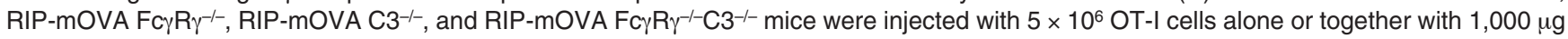
anti-OVA IgG. Fractions below bars indicate the number of diabetic mice over the total number treated. Diabetes occurred in $100 \%$ of antibodytreated WT RIP-mOVA mice compared with $41 \%$ of $\mathrm{Fc \gamma R} \gamma^{-1-}$, 35\% of $\mathrm{C}^{-1-}$, and $0 \%$ of $\mathrm{Fc \gamma R} \gamma^{-1-} \mathrm{C}^{-/-}$mice $\left(P=2 \times 10^{-6}, 5 \times 10^{-7}\right.$, and $8 \times 10^{-10}$, respectively). (B) Survival of WT, Fc $\gamma \mathrm{R}^{-1-}$, and $\mathrm{C}^{-/-}$mice. Kaplan-Meier curves of RIP-mOVA mice (black) compared with RIP-mOVA Fc $\mathrm{R}^{-1-}$ mice (gray, left) and RIP-mOVA C3 $3^{-/}$mice (gray, right) after transfer of OT-I cells and anti-OVA IgG $\left(^{\star \star \star} P=1 \times 10^{-4}\right)$. Diabetes was severe and usually lethal in WT mice. In contrast, disease severity was attenuated in $\mathrm{Fc} \gamma \mathrm{R}^{-/-}$and $\mathrm{C}^{-/-}$mice, with no mice developing fatal diabetes. 
Table 1

Histopathological scores of mice treated with OT-I cells with or without anti-OVA

\begin{tabular}{|c|c|c|c|}
\hline Treatment & Genotype & Insulitis score & Perivascular and acinar infiltration score \\
\hline \multirow[t]{3}{*}{ OT-I cells } & RIP-mOVA WT & $0.16 \pm 0.12$ & $0.71 \pm 0.28$ \\
\hline & RIP-mOVA Fc $\gamma \mathrm{R}^{-/-}$ & $0.17 \pm 0.13$ & $0.86 \pm 0.60$ \\
\hline & $\mathrm{RIP}-\mathrm{mOVA} \mathrm{C3} 3^{-1-}$ & $0.40 \pm 0.33$ & $1.07 \pm 0.29$ \\
\hline \multirow[t]{3}{*}{ OT-I cells + anti-OVA IgG } & RIP-mOVA WT & $1.56 \pm 0.59$ & $1.98 \pm 0.40$ \\
\hline & RIP-mOVA Fc $\gamma \mathrm{R}^{-/-}$ & $0.71 \pm 0.47$ & $1.33 \pm 0.53$ \\
\hline & RIP-mOVA C3 ${ }^{-1-}$ & $0.95 \pm 0.82$ & $1.33 \pm 0.53$ \\
\hline
\end{tabular}

Insulitis was attenuated in $\mathrm{FC \gamma R} \gamma^{-/}$and $\mathrm{C}^{-/-}$mice transferred with anti-OVA IgG and OT-I cells $(P=0.015$ and 0.079 versus WT, respectively, for insulitis scores). In mice treated with OT-I cells alone, insulitis scores were significantly enhanced in $\mathrm{C} 3^{-/-}$mice $\left(P=0.039\right.$, $3^{-1-}$ versus WT).

Antibody-mediated cross-priming and diabetes is inbibited by Fc $\gamma$ RIIB. The ability of murine anti-OVA antibodies to trigger OT-I cell-mediated diabetes was further addressed in RIP-mOVA mice lacking the inhibitory Fc $\gamma$ RIIB. We have shown elsewhere that RIP-mOVA Fc $\gamma \mathrm{RIIB}^{-/}$ animals are more sensitive to antibody-induced diabetes than WT RIP-mOVA mice (7). In these studies, a 10-fold-reduced dose of the rabbit polyclonal anti-OVA IgG $(100 \mu \mathrm{g})$ was subdiabetogenic in WT RIP-mOVA recipients of OT-I cells but was fully diabetogenic in mice lacking Fc $\gamma$ RIIB. Similarly, the murine polyclonal anti-OVA IgG exhibited enhanced pathogenicity in RIP-mOVA Fc $\gamma \mathrm{RIIB}^{-/-}$animals, with $50 \%$ of the mice developing diabetes after the transfer of OT-I cells and administration of a reduced dose $(1 \mathrm{mg})$ of the murine antibody (Figure 8A). At this reduced dose of murine antiOVA IgG, WT RIP-mOVA mice did not develop diabetes, consistent with a tolerogenic role for Fc $\gamma$ RIIB. In addition to the murine polyclonal anti-OVA IgG, 2 murine monoclonal anti-OVA antibodies of the IgG1 and IgG2b subclasses were developed that demonstrated OVA-binding activities similar to the murine polyclonal antibody (Supplemental Figure 2B). These mAbs induced diabetes in WT RIP-mOVA recipients ( 2 of 11) and showed enhanced pathogenicity in RIP-mOVA Fc $\gamma \mathrm{RIIB}^{-/}$mice (4 of 8) (Figure 8A). However, disease induction required higher doses of these $2 \mathrm{mAbs}$, which could be due to their epitope specificity, low avidity, or heavy chain subclass or instead might indicate that pathogenicity is favored by the increased valence provided by polyclonal antibodies.

\section{Figure 7}

Antibody-enhanced OT-I cell proliferation and effector cell differentiation is dependent on activating $\mathrm{FC}_{\boldsymbol{c}} \gamma$ receptors. (A and $\mathbf{B}$ ) OT-I cell proliferative responses in WT, $\mathrm{FC} \gamma \mathrm{R}^{-1-}$, and $\mathrm{C}^{-/-}$mice. Flow cytometric analysis of pancreatic lymph node cells isolated from RIP-mOVA, RIP-mOVA FcyR $\gamma^{-1-}$, and RIP-mOVA C3 $3^{-1-}$ mice (A) and ZVAD-treated and untreated RIP-mOVA C3 $3^{-1-}$ mice (B) 3 days after transfer of CFSElabeled OT-I cells and anti-OVA IgG. The percentage of cells divided (A) and the numbers in the histogram (B) were calculated from FACS plots gated on $\mathrm{CD}^{+}{ }^{+} \mathrm{CFSE}{ }^{+}$cells found after the undivided peak. Bars show mean $\pm \mathrm{SD}$ for at least 5 mice per treatment group. ${ }^{*} P=0.033$; ${ }^{\dagger} 0.0085 ;{ }^{* \star} P=0.00040 ;{ }^{\#} P=0.00060$; NS: $P=0.46$. Histogram represents 1 of 2 independent experiments. Activating $F c \gamma R s$ were required for antibody-enhanced proliferation, whereas $\mathrm{C} 3$ negatively regulated T cell proliferation in a ZVAD-inhibitable manner. (C) OT-I cell effector differentiation in WT, $\mathrm{F} C \gamma \mathrm{R}^{-1-}$, and $\mathrm{C}^{-1-}$ mice. Intracellular IFN- $\gamma$ staining of pancreatic lymph node cells isolated from mice 5 days after treatment. The percentage of cells producing IFN- $\gamma$ was calculated from IFN- $\gamma$-positive cells among $C D 8^{+} \mathrm{V} \alpha 2^{+} \mathrm{V} \beta 5^{+}$-gated populations. Bars show mean \pm SD for at least 3 mice per group. ${ }^{* \star} P=1.06 \times 10^{-6}$; $\dagger+P=0.00048 ; \# P=0.016 ;$; $P=0.037$; NS: $P=0.28$. Antibody enhancement of IFN- $\gamma$ production was intact in $\mathrm{C}^{-/-}$but not $\mathrm{Fc} \gamma \mathrm{R} \gamma^{-/-}$mice.
To directly investigate the cross-priming ability of murine antiOVA IgG, OT-I cell effector differentiation in the pancreatic lymph nodes of RIP-mOVA Fc $\gamma \mathrm{RIIB}^{-/}$and WT RIP-mOVA mice was compared. Consistent with diabetes incidence, OT-I cell effector differentiation was induced in RIP-mOVA Fc $\gamma \mathrm{RIIB}^{-/-}$but not in WT
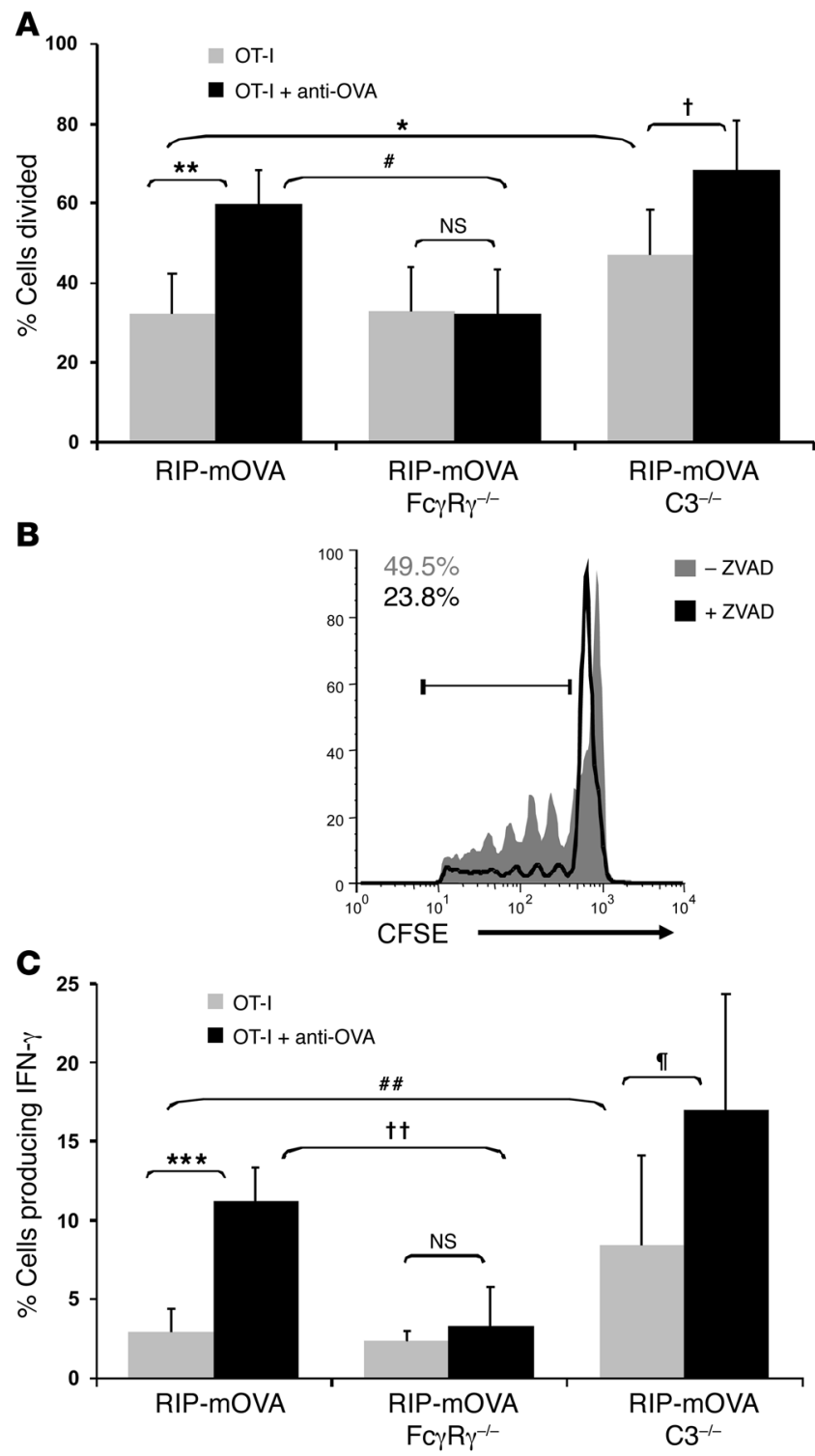
A

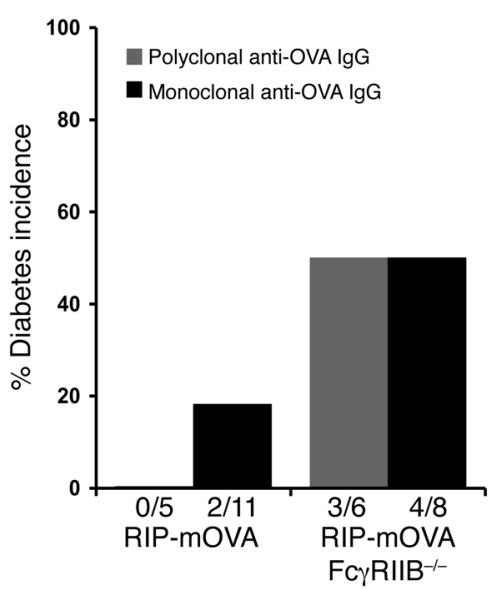

B

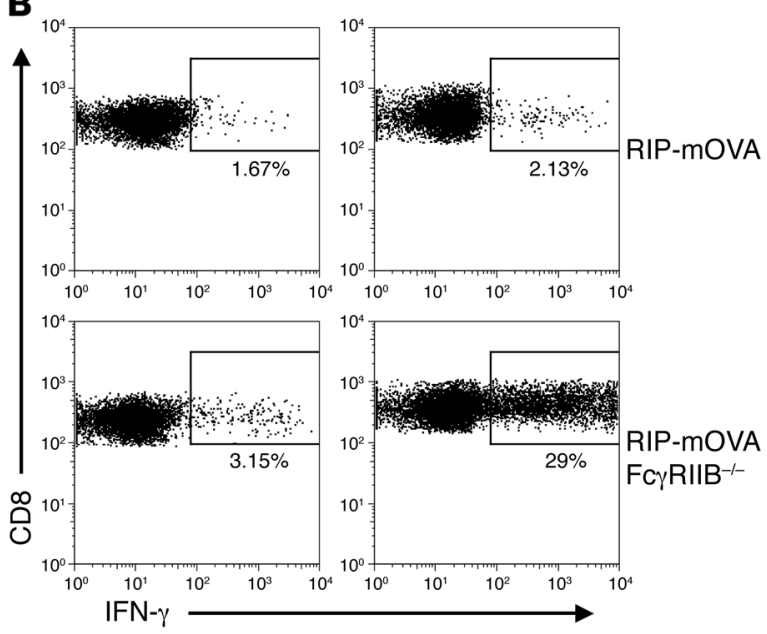

RIP-mOVA recipients of OT-I cells and $1 \mathrm{mg}$ murine polyclonal anti-OVA IgG (Figure 8B). These data are consistent with a role for Fc $\gamma$ RIIB in limiting antibody-mediated cross-priming.

\section{Discussion}

Using a model of peripheral tolerance, we show that autoreactive antibody can drive T cell-mediated autoimmunity. In this system, $\mathrm{CD} 11 \mathrm{c}^{+} \mathrm{DCs}$ are demonstrated to be the APCs responsible for the cross-presentation of self antigen under both tolerogenic and diabetogenic conditions, since under both conditions $\mathrm{T}$ cell proliferation was abolished in DC-depleted RIP-mOVA/CD11c-DTR mice. Furthermore, we have specifically determined that antibody-mediated cross-presentation of self antigen in vivo is accomplished by activating Fc $\gamma$ Rs and not by complement C3-mediated pathways. ZVAD treatment abrogated antibody-enhanced $\mathrm{T}$ cell priming, indicating that activating $\mathrm{F} c \gamma \mathrm{Rs}$ are enhancing the cross-presentation of antibody-opsonized apoptotic material.

Previous studies using cultured DCs have shown that self antigencontaining ICs are strikingly more potent than free antigen in the restimulation of autoreactive $\mathrm{CD}^{+}$and $\mathrm{CD}^{+} \mathrm{T}$ cell clones $(39,40)$. Our data provide direct in vivo evidence for IC-mediated modulation of self antigen presentation to potentially autoaggressive $\mathrm{T}$ cells. This could be accomplished by quantitative enhancement of antigen presentation via Fc $\gamma \mathrm{R}$-mediated uptake, which would overcome the threshold for activation of naive $\mathrm{T}$ cells that are otherwise quiescent toward self antigen. In addition, $\mathrm{F}_{\mathrm{C}} \mathrm{R}$-mediated activation

\section{Figure 8}

FC $\gamma$ RIIB negatively regulates antibody-mediated OT-I cell priming. (A) Diabetes incidence. RIP-mOVA or RIP-mOVA Fc $\gamma \mathrm{RIIB}^{-/-}$mice were injected with $5 \times 10^{6}$ OT-I cells plus either $1 \mathrm{mg}$ murine polyclonal antiOVA IgG or murine monoclonal anti-OVA IgG. For the murine monoclonal anti-OVA IgG, $6 \mathrm{WT}$ and $5 \mathrm{Fc}_{\mathrm{R}} \mathrm{RIIB}^{-/-}$mice were transferred with $18 \mathrm{mg}$ anti-OVA IgG2b, and 5 WT and $3 \mathrm{Fc}_{\mathrm{RIIB}}{ }^{--}$mice were transferred with $42 \mathrm{mg}$ anti-OVA IgG1. Fractions below bars indicate the number of diabetic mice over the total number treated. Both the murine polyclonal antibodies and mAbs showed increased diabetogenicity in mice lacking FcyRIIB. (B) OT-I cell effector differentiation. Intracellular IFN- $\gamma$ staining on pancreatic lymph node OT-I cells isolated from mice 5 days after transfer of OT-I cells alone or together with $1 \mathrm{mg}$ murine polyclonal anti-OVA IgG. Dot plots are gated on $C D 8^{+} \mathrm{V} \alpha 2^{+} \mathrm{V} \beta 5^{+}$cells.

of DCs could also alter the tolerogenic outcome of cognate DC-T cell interactions by the induction of enhanced costimulatory capacity and proinflammatory cytokine production. We show here that RIP-mOVA mice lacking the inhibitory Fc $\gamma$ RIIB exhibit enhanced antibody-mediated cross-priming and increased diabetes sensitivity. We show elsewhere that Fc $\gamma$ RIIB on DCs limits IC-mediated T cell effector responses by both augmentation of DC activation (signal 2) and quantitative reduction of antigen presentation (signal 1) (7).

Steady-state cross-presentation of OVA to the OT-I cells was increased in RIP-mOVA C3 $3^{-/}$mice in a ZVAD-inhibitable manner, revealing complement as a likely negative regulator of the benign clearance of apoptotic cells in vivo. Complement is known to enhance the uptake of apoptotic cells and inhibit DC activation in vitro $(41,42)$, via C1qR $(43,44)$ and/or C3bi receptors, including CD11b and CD11c $(41,42)$. Our data suggest that the engagement of receptors for $\mathrm{C} 3$ products on DCs inhibits the expansion and effector differentiation of responding $\mathrm{T}$ cells, thus insuring that peripheral tolerance toward apoptotic self material is maintained. Loss of this inhibitory pathway in human complement deficiency states may lead to the loss of B and T cell tolerance (12-14) and the increased incidence of SLE in these individuals (20). In addition, RIP-mOVA C3 ${ }^{-/}$mice had only an $11 \%$ and $35 \%$ diabetes incidence when transferred with OT-I cells alone or together with anti-OVA IgG, respectively, despite accumulation of OT-I effector cells in both groups. Thus, islet cell antibodies must make additional contributions to disease other than their effects on $\mathrm{T}$ cell priming. In this capacity, complement is likely proinflammatory, potentially promoting the recruitment, activation, and persistence of macrophages, neutrophils, and effector T cells in the pancreatic islets (10, 44-47).

Cumulatively, these data provide proof of principle for a pathogenic role for self-reactive antibodies, activating Fc $\gamma$ Rs and complement in altering the balance of peripheral $\mathrm{T}$ cell tolerance maintained by cross-presenting DCs. It must be noted that this model system involves high numbers of high-avidity transgenic $\mathrm{T}$ cells, and thus it remains to be seen whether endogenous self-reactive, presumably low-affinity, $T$ cells can be activated in the presence of self-reactive antibodies. Autoantibodies are often found in primarily $\mathrm{T}$ cell-mediated autoimmune diseases such as type 1 diabetes, multiple sclerosis, and rheumatoid arthritis. Yet the importance of these antibodies has been disputed in part because animal models of these illnesses have shown that disease can be adoptively transferred with effector $\mathrm{T}$ cells but not with antibodies. Based on our findings, autoantibodies that lack intrinsic pathogenicity may in fact not only be markers of disease but may actively contribute to disease by targeting self antigen to $\mathrm{F} c \gamma$ Rs on DCs in the lymph node. 
Mechanistic studies in murine models of nephritis (48) and diabetes (49) have found that self-reactive B cells can promote T cell-mediated diseases in their roles as APCs. Consistent with this notion, insulinspecific IgM B cell receptor-bearing (BCR-bearing) transgenic mice developed accelerated diabetes in the NOD background in the absence of circulating secreted antiinsulin antibodies (50). In these models, it is thought that BCR-mediated uptake of soluble self antigen induces ITAM-mediated B cell activation and MHC class II-restricted antigen presentation, empowering these cells as potent APCs for $\mathrm{CD}^{+} \mathrm{T}$ cells. Targeted elimination of the humoral response by $\mathrm{B}$ cell depletion has demonstrated early clinical promise in rheumatoid arthritis (51) and is currently under investigation in type 1 diabetes. Targeting of DCs, however, provides some theoretical advantages, since DCs but not $\mathrm{B}$ cells are capable of both phagocytosis and cross-presentation. For instance, T cell activation triggered by uptake of antibody-opsonized apoptotic cells would be accomplished by DCs expressing Fc $\gamma$ Rs and not by BCR-mediated pathways. Since DCs are a critical component in the initial priming of $T$ cells by self antigen in the periphery, we suggest that blocking antibody-mediated DC activation could uncouple the humoral effector response from the $\mathrm{T}$ cell response, thereby preventing disease progression. In diabetes specifically, the appearance of insulinreactive antibodies often predates development of overt disease (52). This invites early preventive intervention that could stop autoreactive antibodies from promoting autospecific $\mathrm{T}$ cell activation, thus potentially tipping the balance back from autoimmunity to tolerance.

\section{Methods}

Mice. OT-I and CD11c-DTR [(Itgax-DTR/GFP)57Lan/J] mice (C57BL/6 background) were purchased from The Jackson Laboratory. RIP-mOVA mice (C57BL/6 background), originally generated by W. Heath and F. Carbone (22), were obtained from T. Ratliff (University of Iowa, Iowa City, Iowa, USA). $\mathrm{C}^{-/-}$mice were a gift from M. Carroll (Harvard Medical School, Cambridge, Massachusetts, USA). RIP-mOVA Fc $\gamma \mathrm{R} \gamma^{-/-}$, RIP-mOVA C3 ${ }^{-/}$, RIP-mOVA Fc $\gamma \mathrm{R}^{-/-\mathrm{C} 3}{ }^{-/-}$, RIP-mOVA Fc $\gamma \mathrm{RIIB}^{-/}$, and RIP-mOVA/CD11c-DTR mice were bred at Columbia University. All animal experiments were performed in compliance with institutional guidelines and approved by Columbia University's Institutional Animal Care and Use Committee.

Diabetes induction. Six- to 8-week-old RIP-mOVA mice were injected i.v. with $5 \times 10^{6}$ OT-I cells either alone or together with i.p. administration of antiOVA IgG. Diabetes was monitored using an Accu-Chek Advantage Glucometer and Chemstrip 2 GP urinalysis strips (Roche Diagnostics). Mice were considered diabetic if any single urinary glucose measurement equaled or exceeded $1,000 \mathrm{mg} / \mathrm{dl}$. OT-I cells were prepared by CD8 ${ }^{+}$MACS (Miltenyi Biotec) separation from the spleens of OT-I transgenic mice (isolated cells were $\left.>95 \% \mathrm{CD}^{+} \mathrm{V} \alpha 2^{+} \mathrm{V} \beta 5^{+}\right)$. Anti-OVA $\mathrm{rIgG}$ was purified by protein $\mathrm{A}$ affinity chromatography from the serum of a hyperimmunized rabbit (Covance). Unless otherwise stated, all mice received $1,000 \mu \mathrm{g}$ purified rabbit anti-OVA IgG or $1,000 \mu \mathrm{g}$ control preimmune rIgG (I5006; Sigma-Aldrich). An F(ab') fragment of the rabbit anti-OVA IgG was prepared by digestion in $50 \mu \mathrm{g} / \mathrm{ml}$ pepsin (Sigma-Aldrich) in a Na-citrate buffer, $\mathrm{pH} 3.5$, for 6 hours at $37^{\circ} \mathrm{C}$, followed by neutralization and buffer exchange into PBS. Murine polyclonal anti-OVA IgG was purified by protein A chromatography from the sera of 30 mice bled one week after completion of a prime/boost immunization with CFA/OVA and incomplete Freund's adjuvant/OVA. Ascites-produced mAbs of the IgG1 (5D12.1) and IgG2b (2B12.33) subclasses were made from screened OVA-specific B cell hybridomas generated by the fusion of splenocytes from an OVA-immunized BALB/c mouse with the hybridoma line SP2/40-Ag14 (ATCC). In some experiments, BMDCs, harvested from GM-CSF-supported cultures on day 7, were replated for 24 hours with either $10 \mu \mathrm{g} / \mathrm{ml}$ OVA (Worthington Biochemical Corp.) or with OVA/anti-OVA
IIgG ICs $(10 \mu \mathrm{g} / \mathrm{ml} / 50 \mu \mathrm{g} / \mathrm{ml})$. Mice were then immunized i.v. with $1 \times 10^{6}$ stimulated BMDCs followed by $5 \times 10^{6}$ OT-I cells.

In vivo T cell proliferation assays. OT-I cells were labeled with CFSE (Molecular Probes; Invitrogen), and $5 \times 10^{6}$ cells were injected i.v. into recipient mice. To assess the effect of antibody on proliferation, mice were coinjected with $1,000 \mu \mathrm{g}$ anti-OVA IgG i.p. In some experiments, mice were treated i.p. with $10 \mu \mathrm{g}$ ZVAD (Z-VAD-FMK; Calbiochem) 18 hours prior to and 24 hours after transfer of T cells. For systemic DC depletion, RIP-mOVA/CD11c-DTR mice were treated i.p. with $4 \mathrm{ng} / \mathrm{g}$ body weight of DT (D0564; Sigma-Aldrich) 18 hours prior to the transfer of T cells. One dose of DT leads to $48-72$ hours of CD11 $c^{+}$cell depletion (31). On day 3 after transfer, flow cytometric analysis identified OT-I populations among lymph node cells using the following $\mathrm{mAbs}$ (BD Biosciences - Pharmingen): anti-CD8 $\alpha$-perCP-Cy5.5 (clone 53-6.7), anti-V $\alpha 2-\mathrm{PE}$ (B20.1), anti-VB5-biotin (MR9-4)/streptavidin-APC.

IFN- $\gamma$ ELISPOT and intracellular staining. Effector responses were assessed 5 days after transfer of OT-I cells and prior to the onset of hyperglycemia or glycosuria. For ELISPOT analysis, $10^{5}$ cells/well were plated on MultiScreenIP plates (Millipore) coated with $15 \mu \mathrm{g} / \mathrm{ml}$ IFN- $\gamma$ capture antibody (AN18; Mabtech) and incubated overnight at $37^{\circ} \mathrm{C}$ with $0.1 \mu \mathrm{M}$ SIINFEKL peptide (New England Peptide Inc.). Spots were detected with $15 \mu \mathrm{g} / \mathrm{ml}$ biotinylated antibody against IFN- $\gamma$ (R4-6A2-biotin; Mabtech), followed by streptavidinALP and then BCIP/NTC substrate (Bio-Rad). Spots were counted manually using a dissecting microscope. For intracellular staining, $2 \times 10^{6} \mathrm{cells} / 500 \mu \mathrm{l}$ complete medium were incubated with $0.1 \mu \mathrm{M}$ SIINFEKL peptide and GolgiStop solution (BD Biosciences) for 6 hours at $37^{\circ} \mathrm{C}$. Cell fixation and permeabilization was done using the Cytofix/Cytoperm Plus kit (BD Biosciences) prior to staining with anti-IFN- $\gamma$-Alexa Fluor 647 (XMG1.2).

Preparation of pancreatic cells. Harvested pancreata were immersed in a solution of $1 \mathrm{mg} / \mathrm{ml}$ liberase RI (Roche Applied Science) and $25 \mu \mathrm{g} / \mathrm{ml}$ DNase I (Roche). After 30 minutes at $37^{\circ} \mathrm{C}$, the tissue was further broken down by drawing through an 18-gauge syringe. Cells were then washed in 5\% FCS and stained for flow cytometric analysis. The protocol was developed by P. Kendall, Vanderbilt University, Nashville, Tennessee, USA (personal communication).

Histopathology. Formalin-fixed pancreatic sections were stained with H\&E. For immunofluorescence, $4 \%$ paraformaldehyde-fixed cryosections were stained with anti-CD8 $\alpha-\mathrm{PE}$ (clone 53-6.7), rabbit anti-OVA IgG (polyclonal; ICN Cappel), and anti-rabbit-Alexa Fluor 488 (A11070; Molecular Probes; Invitrogen). Digital images were obtained with an E500 fluorescence microscope (Nikon) equipped with the RT SPOT digital camera/software package (Diagnostic Instruments Inc.).

Histopathological assessment of insulitis. H\&E-stained pancreatic sections from mice sacrificed 5 days after transfer of OT-I cells alone or together with antiOVA IgG were scored in a blinded manner. The insulitis score is a weighted average of the degree of insulitis per islet, with at least 300 islets examined per treatment group. Insulitis was graded as 0 (no infiltration), 1 (peri-insulitis), 2 ( $<50 \%$ penetrance of the islet), 3 (complete penetrance of the islet). Perivascular and acinar infiltration were each graded on a scale of increasing intensity from 0 to 3 , and the values were then averaged for each treatment group.

Statistics. Differences between groups were evaluated using a 1-tailed unpaired Student's $t$ test, except for the results shown in Figure 6A, where $P$ values were calculated using Fisher's exact test. Kaplan-Meier survival curves were constructed using GraphPad Prism 4.0 software. Survival curve $P$ values were calculated using a 2 -tailed log-rank test.

\section{Acknowledgments}

We thank Kevan Herold for helpful discussions, Steve Greenberg for critical reading of this manuscript, and Anamika Gavahne and Matt Downie for their technical assistance. This work was supported by NIH grants T32 HL 072739 and T32 AI 07525 (to D.D. Desai and G. Catalano); by NIH grants R01 NCI CA94037, R01 NIDDK 
DK70999, and P01AI50514 (to R. Clynes); and by a Pilot and Feasibility Award of the Diabetes and Endocrinology Research Center of Columbia University (NIH DK63608) (to R. Clynes). S. Jung is the incumbent of the Pauline Recanati Career Development Chair.

Received for publication June 21, 2006, and accepted in revised form February 14, 2007.

1. Bergtold, A., Desai, D.D., Gavhane, A., and Clynes, R. 2005. Cell surface recycling of internalized antigen permits dendritic cell priming of B cells. Immunity. 23:503-514.

2. Amigorena, S. 2002. Fc gamma receptors and cross-presentation in dendritic cells. J. Exp. Med. 195:F1-F3.

3. Regnault, A., et al. 1999. Fcgamma receptor-mediated induction of dendritic cell maturation and major histocompatibility complex class I-restricted antigen presentation after immune complex internalization. J. Exp. Med. 189:371-380.

4. Sedlik, C., et al. 2003. A critical role for Syk protein tyrosine kinase in Fc receptor-mediated antigen presentation and induction of dendritic cell maturation. J. Immunol. 170:846-852.

5. Dhodapkar, K.M., et al. 2005. Selective blockade of inhibitory Fcgamma receptor enables human dendritic cell maturation with IL- 12 p70 production and immunity to antibody-coated tumor cells. Proc. Natl. Acad. Sci. U. S. A. 102:2910-2915.

6. Kalergis, A.M., and Ravetch, J.V. 2002. Inducing tumor immunity through the selective engagement of activating Fcgamma receptors on dendritic cells. J. Exp. Med. 195:1653-1659.

7. Desai, D.D., et al. 2007. FC $\gamma$ receptor IIB on dendritic cells enforces peripheral tolerance by inhibiting effector T cell responses. J. Immunol. In press.

8. Rafiq, K., Bergtold, A., and Clynes, R. 2002. Immune complex-mediated antigen presentation induces tumor immunity. J. Clin. Invest. 110:71-79. doi:10.1172/JCI200215640.

9. Kim, A.H., et al. 2004. Complement C5a receptor is essential for the optimal generation of antiviral CD8+ T cell responses. J. Immunol. 173:2524-2529.

10. Kopf, M., Abel, B., Gallimore, A., Carroll, M., and Bachmann, M.F. 2002. Complement component C3 promotes T-cell priming and lung migration to control acute influenza virus infection. Nat. Med. 8:373-378.

11. Suresh, M., et al. 2003. Complement component 3 is required for optimal expansion of CD8 T cells during a systemic viral infection. J. Immunol. 170:788-794.

12. Prodeus, A.P., et al. 1998. A critical role for complement in maintenance of self-tolerance. Immunity. 9:721-731.

13. Sohn, J.H., et al. 2003. Tolerance is dependent on complement $\mathrm{C} 3$ fragment $\mathrm{iC} 3 \mathrm{~b}$ binding to antigenpresenting cells. Nat. Med. 9:206-212.

14. Hammerberg, C., Katiyar, S.K., Carroll, M.C., and Cooper, K.D. 1998. Activated complement component 3 (C3) is required for ultraviolet induction of immunosuppression and antigenic tolerance. J. Exp. Med. 187:1133-1138.

15. Quartier, P., Potter, P.K., Ehrenstein, M.R., Walport, M.J., and Botto, M. 2005. Predominant role of IgMdependent activation of the classical pathway in the clearance of dying cells by murine bone marrow-derived macrophages in vitro. Eur. J. Immunol. 35:252-260.

16. Taylor, P.R., et al. 2000. A hierarchical role for classical pathway complement proteins in the clearance of apoptotic cells in vivo. J. Exp. Med. 192:359-366.

17. Pittoni, V., and Valesini, G. 2002. The clearance of apoptotic cells: implications for autoimmunity. Autoimmun. Rev. 1:154-161.

18. Mevorach, D., Mascarenhas, J.O., Gershov, D., and
Address correspondence to: Raphael Clynes, P \& S Building, Room 8-510, Columbia University, College of Physicians and Surgeons, 630 West 168th Street, New York, New York, USA. Phone: (212) 305-5289; Fax: (212) 305-1392; E-mail: rc645@ columbia.edu.

D.D. Desai and R. Clynes contributed equally to this work.
Elkon, K.B. 1998. Complement-dependent clearance of apoptotic cells by human macrophages. J. Exp. Med. 188:2313-2320.

19. Mevorach, D. 2003. Systemic lupus erythematosus and apoptosis: a question of balance. Clin. Rev. Allergy Immunol. 25:49-60.

20. Manderson, A.P., Botto, M., and Walport, M.J. 2004 The role of complement in the development of systemic lupus erythematosus. Annu. Rev. Immunol. 22:431-456.

21. Botto, M. 1998. C1q knock-out mice for the study of complement deficiency in autoimmune disease. Exp. Clin. Immunogenet. 15:231-234.

22. Carroll, M.C. 2000. The role of complement in B cell activation and tolerance. Adv. Immunol. 74:61-88.

23. Kurts, C., et al. 1996. Constitutive class I-restricted exogenous presentation of self antigens in vivo. J. Exp. Med. 184:923-930.

24. Kurts, C., Heath, W.R., Kosaka, H., Miller, J.F., and Carbone, F.R. 1998. The peripheral deletion of autoreactive CD8+ T cells induced by cross-presentation of self-antigens involves signaling through CD95 (Fas, Apo-1). J. Exp. Med. 188:415-420.

25. Behrens, G.M., et al. 2004. Helper requirements for generation of effector CTL to islet beta cell antigens. J. Immunol. 172:5420-5426.

26. Kurts, C., Kosaka, H., Carbone, F.R., Miller, J.F., and Heath, W.R. 1997. Class I-restricted crosspresentation of exogenous self-antigens leads to deletion of autoreactive CD8(+) T cells. J. Exp. Med. 186:239-245.

27. Turley, S., Poirot, L., Hattori, M., Benoist, C., and Mathis, D. 2003. Physiological beta cell death triggers priming of self-reactive $\mathrm{T}$ cells by dendritic cells in a type-1 diabetes model. J. Exp. Med. 198:1527-1537.

28. Davey, G.M., et al. 2002. Peripheral deletion of autoreactive CD8 $\mathrm{T}$ cells by cross presentation of self-antigen occurs by a Bcl-2-inhibitable pathway mediated by Bim. J. Exp. Med. 196:947-955.

29. Kurts, C., Cannarile, M., Klebba, I., and Brocker, T. 2001. Dendritic cells are sufficient to cross-present self-antigens to CD8 T cells in vivo. J. Immunol. 166:1439-1442.

30. Belz, G.T., et al. 2002. The CD8alpha(+) dendritic cell is responsible for inducing peripheral self-tolerance to tissue-associated antigens. J. Exp. Med. 196:1099-1104.

31. Jung, S., et al. 2002. In vivo depletion of CD11c(+) dendritic cells abrogates priming of CD8(+) T cells by exogenous cell-associated antigens. Immunity. 17:211-220.

32. van Rijt, L.S., et al. 2005. In vivo depletion of lung $\mathrm{CD} 11 \mathrm{c}+$ dendritic cells during allergen challenge abrogates the characteristic features of asthma. J. Exp. Med. 201:981-991.

33. Zammit, D.J., Cauley, L.S., Pham, Q.M., and Lefrancois, L. 2005. Dendritic cells maximize the memory CD8 $\mathrm{T}$ cell response to infection. Immunity. 22:561-570.

34. Probst, H.C., and van den Broek, M. 2005. Priming of CTLs by lymphocytic choriomeningitis virus depends on dendritic cells. J. Immunol. 174:3920-3924.

35. Probst, H.C., et al. 2005. Histological analysis of CD11c-DTR/GFP mice after in vivo depletion of dendritic cells. Clin. Exp. Immunol. 141:398-404.

36. Takai, T., Li, M., Sylvestre, D., Clynes, R., and Ravetch, J.V. 1994. FcR gamma chain deletion results in pleiotrophic effector cell defects. Cell. 76:519-529.

37. Fukuyama, H., Nimmerjahn, F., and Ravetch, J.V. 2005. The inhibitory Fcgamma receptor modulates autoimmunity by limiting the accumulation of immunoglobulin G+ anti-DNA plasma cells. Nat. Immunol. 6:99-106.

38. Wessels, M.R., et al. 1995. Studies of group B streptococcal infection in mice deficient in complement component $\mathrm{C} 3$ or $\mathrm{C} 4$ demonstrate an essential role for complement in both innate and acquired immunity. Proc. Natl. Acad. Sci. U. S. A. 92:11490-11494.

39. Reijonen, H., Daniels, T., Lernmark, A., and Nepom, G. 2000. GAD65-specific autoantibodies enhance the presentation of an immunodominant T-cell epitope from GAD65. Diabetes. 49:1621-1626.

40. Kita, H., et al. 2002. Identification of HLA-A2restricted $\mathrm{CD} 8(+)$ cytotoxic $\mathrm{T}$ cell responses in primary biliary cirrhosis: $\mathrm{T}$ cell activation is augmented by immune complexes cross-presented by dendritic cells. J. Exp. Med. 195:113-123.

41. Morelli, A.E., et al. 2003. Internalization of circulating apoptotic cells by splenic marginal zone dendritic cells: dependence on complement receptors and effect on cytokine production. Blood. 101:611-620.

42. Skoberne, M., et al. 2006. The apoptotic cell receptor CR3, but not alphavbeta5, is a regulator of human dendritic cell immunostimulatory function. Blood. 108:947-955.

43. Norsworthy, P.J., et al. 2004. Murine CD93 (C1qRp) contributes to the removal of apoptotic cells in vivo but is not required for C1q-mediated enhancement of phagocytosis. J. Immunol. 172:3406-3414.

44. Botto, M., et al. 1998. Homozygous C1q deficiency causes glomerulonephritis associated with multiple apoptotic bodies. Nat. Genet. 19:56-59.

45. Tsuji, R.F., et al. 1997. Required early complement activation in contact sensitivity with generation of local C5-dependent chemotactic activity, and late T cell interferon gamma: a possible initiating role of B cells. J. Exp. Med. 186:1015-1026.

46. Tsuji, R.F., Kikuchi, M., and Askenase, P.W. 1996. Possible involvement of C5/C5a in the efferent and elicitation phases of contact sensitivity. J. Immunol. 156:4444-4450.

47. Prodeus, A.P., Zhou, X., Maurer, M., Galli, S.J., and Carroll, M.C. 1997. Impaired mast cell-dependent natural immunity in complement C3-deficient mice. Nature. 390:172-175.

48. Chan, O.T., Hannum, L.G., Haberman, A.M., Madaio, M.P., and Shlomchik, M.J. 1999. A novel mouse with B cells but lacking serum antibody reveals an antibody-independent role for B cells in murine lupus. J. Exp. Med. 189:1639-1648.

49. Wong, F.S., et al. 2004. Investigation of the role of Bcells in type 1 diabetes in the NOD mouse. Diabetes. 53:2581-2587.

50. Hulbert, C., Riseili, B., Rojas, M., and Thomas, J.W. 2001. B cell specificity contributes to the outcome of diabetes in nonobese diabetic mice. J. Immunol. 167:5535-5538

51. Edwards, J.C., et al. 2004. Efficacy of B-cell-targeted therapy with rituximab in patients with rheumatoid arthritis. N. Engl. J. Med. 350:2572-2581.

52. Palmer, J.P., et al. 1983. Insulin antibodies in insulin-dependent diabetics before insulin treatment. Science. 222:1337-1339. 